\title{
Kinetics and thermodynamic studies of the bromination of sultams using a spectroscopic technique
}

\author{
Kareem Sh. Ahmed ${ }^{1}$,Hassan A. Mohammed ${ }^{2}$, Shireen I. Hamadamin ${ }^{3}$ \\ (Department of Chemistry, College of Science, Salahaddin University, Erbil, Kurdistan, Iraq)
}

\begin{abstract}
Kinetics and thermodynamic studies of bromination of $N$-( $p$-substituted phenyl) $-3,5$ - dimethyl $-1,1$ dioxo-1,2-thiazine $\left(\mathrm{C}_{4} \mathrm{H}_{2}\left(\mathrm{CH}_{3}\right)_{2} \mathrm{SO}_{2} \mathrm{~N}_{6} \mathrm{C}_{6} \mathrm{H}_{4} \mathrm{X}\right) ;\{\mathrm{X}=\mathrm{H}, \mathrm{p}$ - $\mathrm{Cl}$, and p-OCH$\}$ by using bromine $\left(\mathrm{Br}_{2}\right)$ in chloroform medium have been investigated by Isolation method the observed rate of bromination, pseudo first order for 1,2-thiazine and $\mathrm{Br}_{2}$ and second order in overall reaction and using spectrophotometric techniques. The reaction rate constant increases with increasing temperature from $273 \mathrm{~K}$ to $318 \mathrm{~K}$. The kinetic and thermodynamic parameters $k, E_{a}, \Delta H^{\#}$ and $\Delta S^{\#}$ have been calculated. The corresponding halogenated 1,2thiazine has been identified as a product of halogenation. A suitable reaction scheme is proposed and an appropriate rate law is deduced to account for the observed kinetic and thermodynamic data.
\end{abstract}

Keywords: Bromination $\left(\mathrm{Br}_{2}\right)$, Kinetic, Sultam, Spectroscopy, Thermodynamic.

\section{Introduction}

Sulfonamides have long been recognized for their wide range of biological activities ${ }^{[1]}$ and are among the most common causes of allergic reactions of drugs. Recently, much interest has been directed to their cyclic counterparts, the sultams, which also exhibit a vast variety of biological activities. A number of substituted sultams have proven to be useful heterocycles for medical applications ${ }^{[2,3]}$. As a consequence, chemical syntheses towards sultams have continued to be an attractive topic for intense research ${ }^{[4]}$.

Sultams $\{1\}$ are inner Sulfonamides in which the S-N bond is part of a ring, the tautomeric forms of sultams, having a sulfur-nitrogen double bond as part of a ring, are called Sultimes $\{2\}$. The chemical composition of which corresponds to the general formula ${ }^{[5]}$ :<smiles>O=S1(=O)CCCCCCC1C1CNS(=O)(=O)N2CCCCCC12</smiles>

Unsaturated sultams prepared from the corresponding sultones, (Sultones are intramolecular cyclic esters of hydroxy sulfonic acids) it has surprisingly been found that unsaturated sultones may be condensed with ammonia or primary amines yielding unsaturated sultams. The reaction proceeds in accordance with the general reaction scheme ${ }^{[6]}$ :

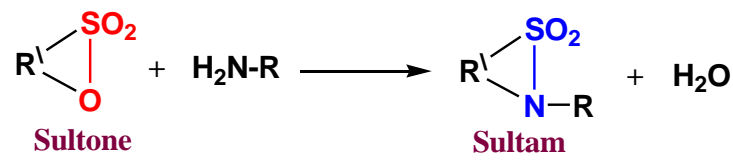

The unsaturated sultams, in accordance with the invention are highly stable and permit further reactions in the sultam ring as well as in the substituents at the sultam nitrogen atom ${ }^{[6]} .1,2$-thiazine is a type of sultams, was prepared by mixing of 4,6-dimethyl-1,2-oxathiine-2,2-dioxide $\{3\}$ with aniline $\{4\}$ or p-substituted aniline and heated for $1.5 \mathrm{hr}$., giving $\mathrm{N}$-(p-substitutedphenyl)-3,5-dimethyl-1,1-dioxo-1,2-thiazine $\{5\}^{[7,8\}}$.<smiles>C[C@H]1C=C[C@H](O)O[Se]1</smiles>

\{3\}

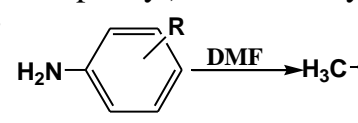

\{4\} R=H

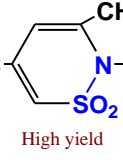

Sultam B R=C

Funghanel and co-worker, used elementary bromine ${ }^{[9]}$ for the bromination of 1,2-thiazine, also using different molar ratio of $\mathrm{N}$-bromosuccinimide, which is high selective brominating agent to obtain the same product with higher yields ${ }^{[10]}$ (scheme 1). 


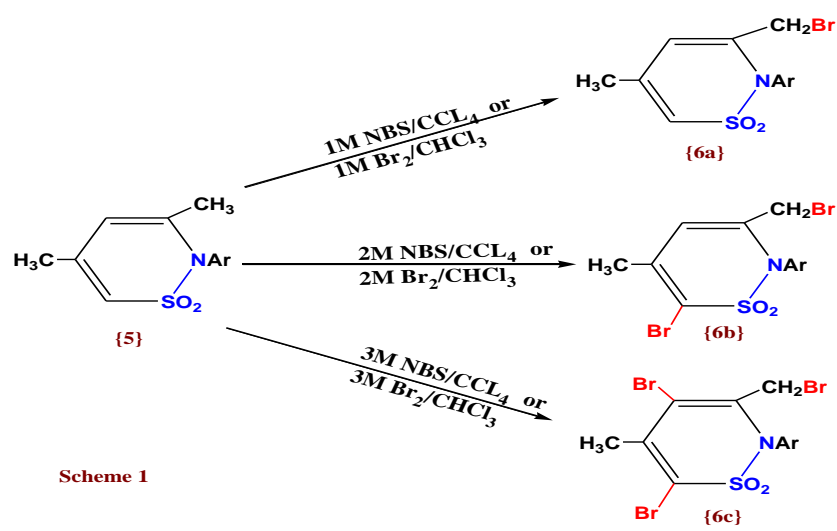

Because of our continuing interest in mild reagents for the introducing of halogens into organic molecules and because only limited kinetic and thermodynamic information is available on sultam reactions with bromine, we found it is important to determine kinetic and thermodynamic parameters of the halogenation reactions of 1,2-thiazine.

\subsection{Chemicals}

\section{Experimental}

All chemicals used were of an analytical grade reagent, and methanol (99.9\% purity) was purchased from TEDIA Company, Inc. (USA). N,N-Dimethylformamide (DMF) 99.8\% from BioSolve. Acetone 99.5\%, Chloroform $>99.4 \%$, bromine $(\mathrm{Br} 2)>97 \%$ hydrochloric acid $(\mathrm{HCl}) 97 \%$ by Fluka., Aniline $90 \%$, Acetic anhydride $99 \%$, Sulphuric acid and sultone $98 \%$ by Sigma Aldrich Co.,4-Chloroaniline, 4-methoxyaniline by Riedel-de Haën, Franç.

\subsection{Synthesis of $\mathrm{N}$-(p-substituted phenyl)-3,5-dimethyl-1,1-dioxo-1,2-thiazine \{5\}A-C}

A mixture of $0.1 \mathrm{~mole}(16 \mathrm{gm})$ sultone $\{3\}$ and 0.1 mole $(9.1 \mathrm{ml})$ of aniline or $\mathrm{p}$-substituted aniline were dissolved in $25 \mathrm{ml} \mathrm{N}, \mathrm{N}$-dimethyl formamide (DMF), the contents reflexed for $1.5 \mathrm{hr}$, then cooled to room temperature and $10 \mathrm{ml}$ of $(0.1 \mathrm{~N}) \mathrm{HCl}$ was added to remove the excess of aniline then the precipitate collected by filtration, washed with cold water dried and recrystallized in methanol ${ }^{[9]}$. The physical properties are shown in table(1).

Table (1): some physical properties of the compounds (Sultam A, B, C)

\begin{tabular}{|l|l|l|l|l|l|l|}
\hline \multicolumn{2}{|l}{ Compounds } & $\begin{array}{l}\text { para- } \boldsymbol{R} \\
(\boldsymbol{p}-\boldsymbol{R})\end{array}$ & $\begin{array}{l}\text { Molecular } \\
\text { formula }\end{array}$ & M.wt (g/mole) & $\begin{array}{l}\text { Yield } \\
\text { \% }\end{array}$ & $\begin{array}{l}\text { 2max } \\
(\text { nm })\end{array}$ \\
\hline \multirow{2}{*}{$\begin{array}{l}\text { Sulta } \\
\text { m }\end{array}$} & $\mathrm{A}$ & $\mathrm{H}$ & $\mathrm{C}_{12} \mathrm{H}_{13} \mathrm{NO}_{2} \mathrm{~S}$ & 235.303 & 53 & 290 \\
\cline { 2 - 8 } & $\mathrm{B}$ & $\mathrm{Cl}$ & $\mathrm{C}_{12} \mathrm{H}_{12} \mathrm{NO}_{2} \mathrm{SCl}$ & 269.749 & 42 & 260 \\
\cline { 2 - 8 } & $\mathrm{C}$ & $\mathrm{OCH}_{3}$ & $\mathrm{C}_{13} \mathrm{H}_{15} \mathrm{NO}_{3} \mathrm{~S}$ & 265.329 & 49 & 260 \\
\hline
\end{tabular}

\subsection{Experimental techniques and apparatus}

The experimental techniques that have been used in kinetics studies to accomplish these measurements are many and varied. The most useful technique that we used in kinetic studies is UV-Vis spectroscopy: since the experiment should be done under isothermal condition, the reactor would be immersed in the thermostated liquid bath.

The UV-visible absorption spectra were measured on a Spectroscan 80D instrument spectrophotometer with serial no.:18-1884-01-0113, with UV-spectroscan software, using $1 \mathrm{~cm}$ matched quartz cells with a homemade cell jacket, made from a thin copper sheet, which was painted by a black dye to minimize the light reflection, connected a thermostated digital circulating bath.

The instrument records the absorbance curve systematically for the product and automatically at fixed cycle time (in sec), between (190-1100)nm. Taking continuous readings until the absorbance remains constant for two hour and this value represents $\left(\mathrm{A}_{\infty}\right)$. All the experiments were repeated at six different temperatures $(273,283,293,298,303,318) \mathrm{K}$, for each reaction.

\subsubsection{Typical kinetic experiment of the molar ratio (1:15) (SultamA : $\left.\mathbf{B r}_{2}\right)$}

The reaction was carried out in a $25 \mathrm{ml}$ conical flask, $0.235 \mathrm{~g}\left(0.001 \mathrm{~mol}, 0.0928 \mathrm{~mol} \mathrm{dm}^{-3}\right)$ of 1,2 -thiazine (Sultam A) and $5 \mathrm{ml}$ of chloroform was added by means of micro burette, the flask was placed inside the automatic liquid bath at $298 \mathrm{~K}$ for thermal equilibration for $30 \mathrm{~min}$ before the experiment.The brominated agent, 
$\left(\mathrm{Br}_{2}\right) 10.77 \mathrm{ml}\left(0.015 \mathrm{~mol}, 1.392 \mathrm{~mol} \mathrm{dm}^{-3}\right)$ was added to the sample solution and quickly mixed then added to the cuvette and capped, the cuvette was inserted into the UV-visible system, It should be mentioned that the wave length $\lambda_{\max }$ measured for the $\mathrm{Br}_{2}$ was $415 \mathrm{~nm}$ in chloroform. Then taking baseline spectrum at full range (190$1100) \mathrm{nm}$ for all the solution mixture to auto zero all the peaks of the reactant solutions, then "start" button was pressed, and the instrument records the absorbance curve systematically for the product, taking continuous readings automatically at fixed cycle time every 600 seconds, until the absorbance remains constant for two hour which represents $\left(A_{\infty}\right)$. All the experiments were repeated at six different temperatures $(273,283,293,298$, 303, 318)K. similar experiment was also performed for sultams B and C.

\subsubsection{Molar ratio (15:1) (SultamA: $\left.\mathrm{Br}_{2}\right)$}

Using concentrations by dissolving $3.5295 \mathrm{~g}\left(0.015 \mathrm{~mol}, 1.4923 \mathrm{~mol} \mathrm{dm}^{-3}\right)$ of 1,2-thiazine (Sultam A) $10 \mathrm{ml}$ of chloroform at $298 \mathrm{~K}$ and the brominated agent, $\left(\mathrm{Br}_{2}\right) 0.0513 \mathrm{ml}\left(0.001 \mathrm{~mol}, 0.0994 \mathrm{~mol} \mathrm{dm}^{-3}\right)$ was added.

\subsubsection{Molar ratio (1:1) (SultamA: $\left.\mathrm{Br}_{2}\right)$}

Using concentrations by dissolving $0.235 \mathrm{~g}\left(0.001 \mathrm{~mol}, 0.197 \mathrm{~mol} \mathrm{dm}^{-3}\right)$ of 1,2 -thiazine (Sultam A) $10 \mathrm{ml}$ of chloroform at $298 \mathrm{~K}$ and the brominated agent, $\left(\mathrm{Br}_{2}\right) 0.0512 \mathrm{ml}\left(0.001 \mathrm{~mol}, 0.1974 \mathrm{~mol} \mathrm{dm}^{-3}\right)$ was added.

\subsection{The brominationusing sultan: $\mathrm{Br}_{2}(1: 15)$ molar ratio}

\section{Results And Discussion}

The bromination of sultams by bromine in chloroform has been kinetically investigated at six different temperatures with excess bromine $\left(\left[\mathrm{Br}_{2}\right] \gg\right.$ [sultam]), at constant temperature. The spectral changes, from the start of the reaction toward the completion, demonstrate very clearly how absorbance changes over time for the brominated sultam (A) at $375 \mathrm{~nm}$, and time course measurement was obtained from the 3-dimensional data, (as shown in two and three dimensional spectrum curves respectively in fig.(1) also for sultam (B) and sultam (C) are shown in the fig. (2) and (3) respectively, shortly after the peaks begin to appear and increase in intensity as a result of the increase of the formation of the product with time. In this way, time course data freely indicate that no equilibrium occurred at all between the product and reactants within the time period studied.

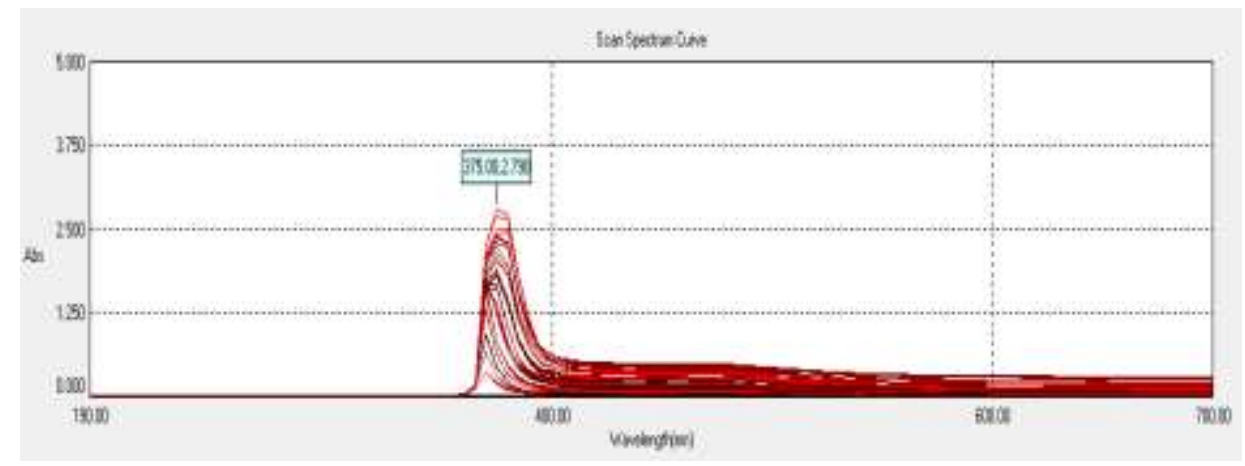

Figure (1)a: two dimensional spectrum for sultam $\mathrm{A}$ at $283 \mathrm{~K},(1: 15)$ ratio.

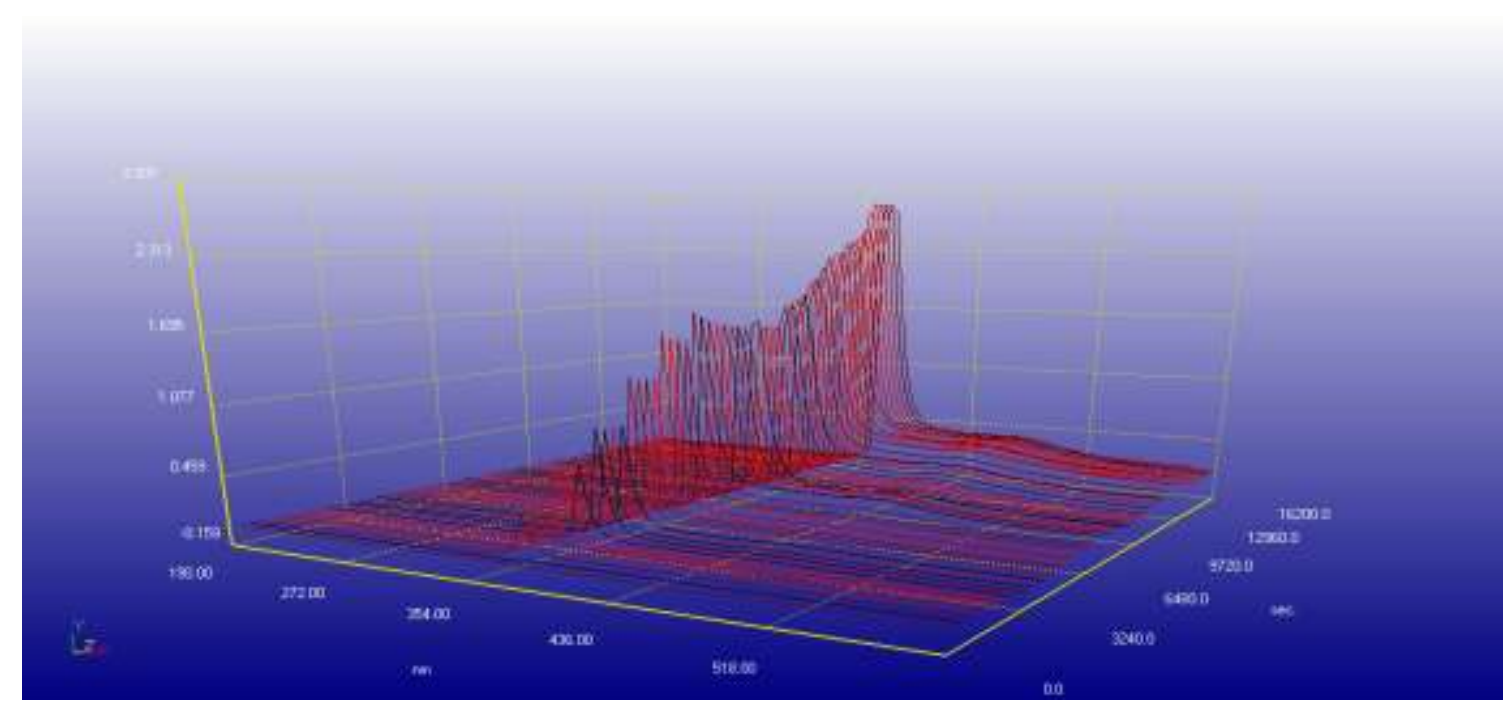

Figure (1)b: three dimensional spectrum for sultam A at 283K, (1:15) ratio. 


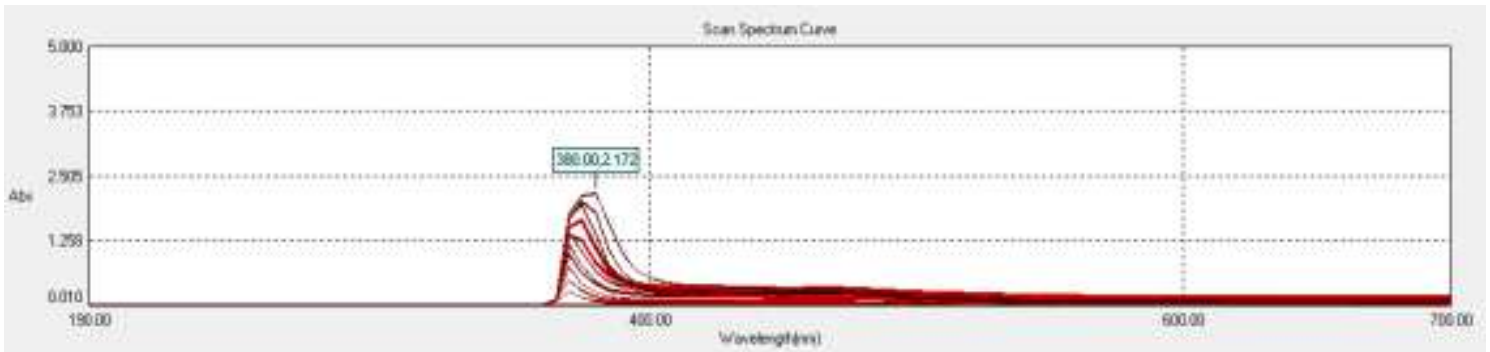

Figure (2)a: two dimensional spectrum for sultam B at 283K, (1:15) ratio.

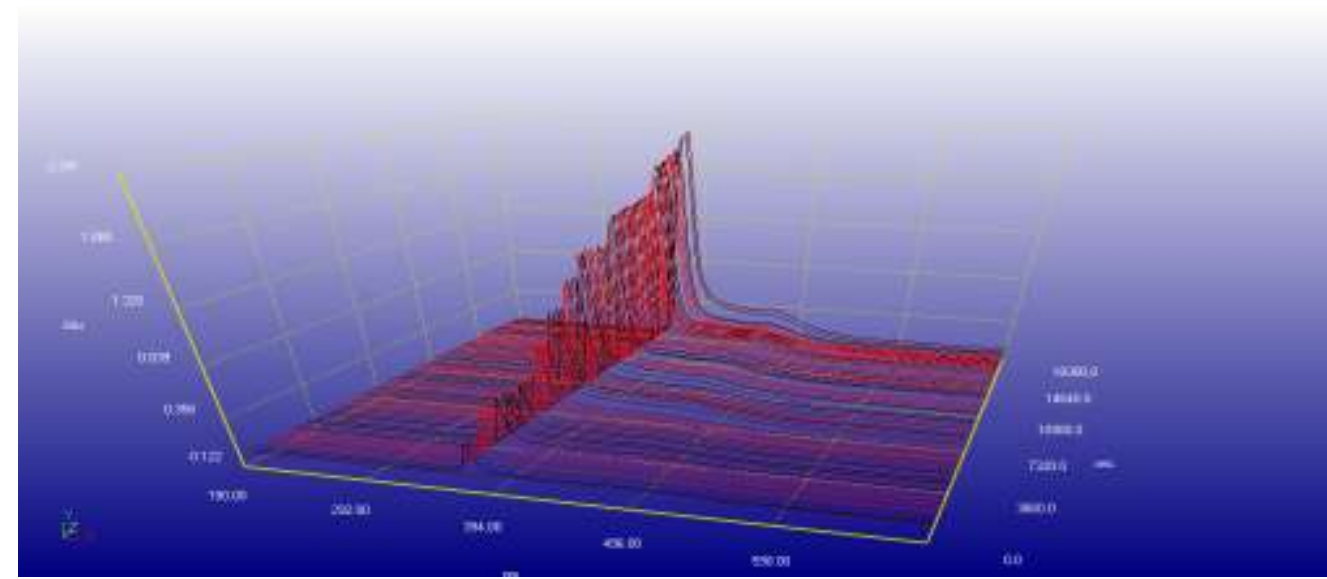

Figure (2)b: three dimensional spectrum for sultam B at 283K, (1:15) ratio.

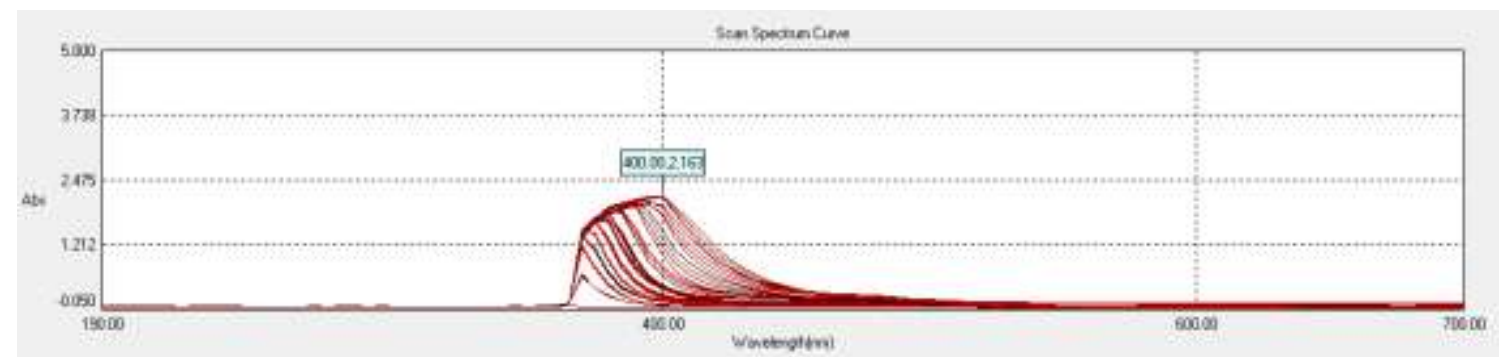

Figure (3)a: two dimensional spectrum for sultam C at 303K, (1:15) ratio.

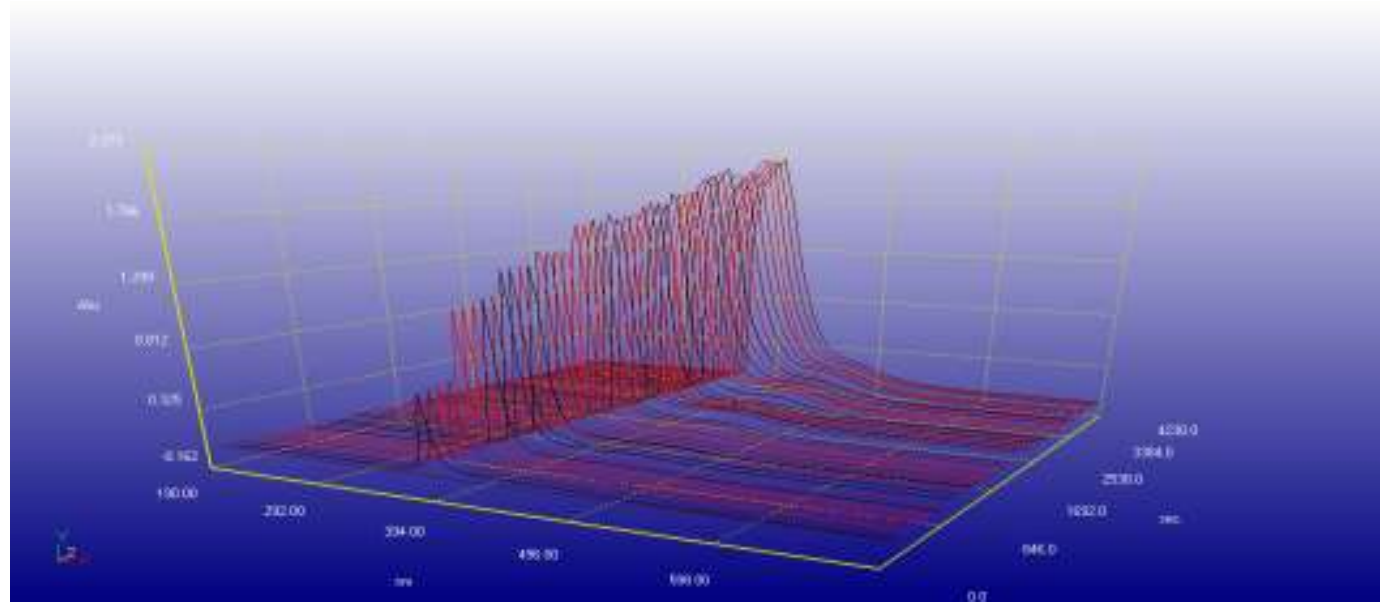

Figure (3)b: three dimensional spectrum for sultam $\mathrm{C}$ at 303K, (1:15) ratio.

The variation of absorbance of the product with time as shown from the fig.(4) the absorbance at $273 \mathrm{~K}$ needs more time for completion as the temperature increase, the amount of molecular interactions also increase and the reaction more quickly goes to product. 


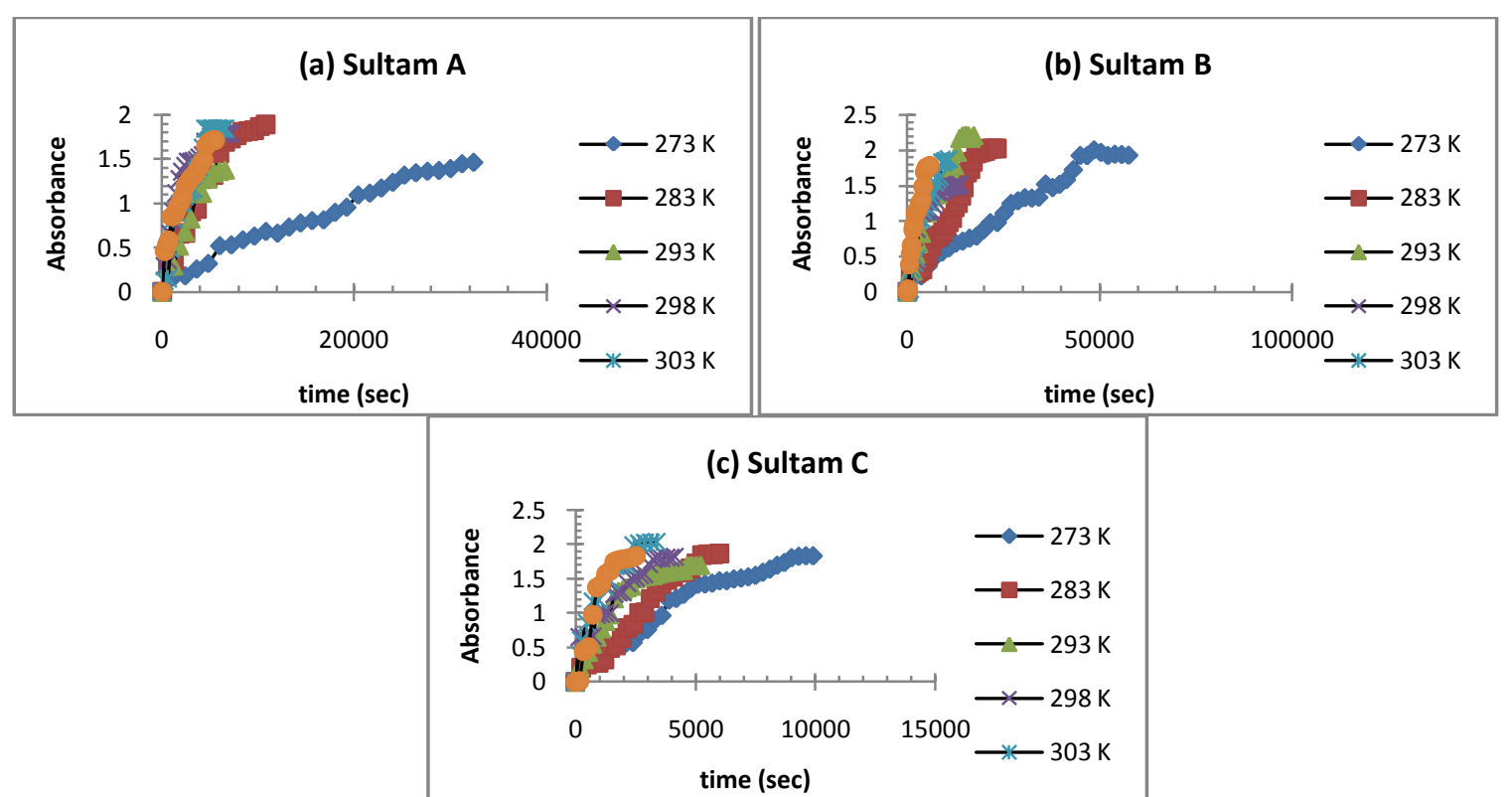

Figure (4): Variation of absorbance of the product with time for bromination of sultams (A, B, C) at different temperature.

The results obtained from the kinetic data for the product of the bromination of sultams were found to follow pseudo first-order kinetics according to the equation (1). The rate constant values (k) at different temperature were calculated for the product from the pseudo first order equation ${ }^{[11,12]}$ :

$\operatorname{Ln}\left(A_{\infty}-A_{t}\right)=\ln A_{\infty}-k t$

Where $\mathrm{A}_{0}$ : Absorbance of the product at zero time, equivalent to base line of product.

$A_{t}$ : Absorbance of the product at any time $(t)$.

$\mathrm{A}_{\infty}$ : Absorbance of the product at infinite time (to), and also equivalent to the initial concentration of reactant (a).

$\mathrm{t}$ : time in sec. $\quad \mathrm{k}$ : rate constant of reaction in $\sec ^{-1}$

$(\mathrm{A} \infty-\mathrm{At})$ : concentration of product at any time, and also equivalent to remaining concentration of reactant $(\mathrm{a}-\mathrm{x})$.

The value of $k$ for each temperature was evaluated from the slope of the linear plots of $\ln \left(A_{\infty}-A_{t}\right)$ against ( $t$ ), the data plots are shown in the fig. (5) and the summary of findings of $k, t_{1 / 2}$, and $\mathrm{R}^{2}$ are given in the table ( $2 a, b$ and $c$ ), where $t_{1 / 2}$ is the half-life of the reaction. $R^{2}$ is the correlation coefficient which is a measure of the goodness-of-fit of the regression and $0 \leq \mathrm{R}^{2} \leq 1$.
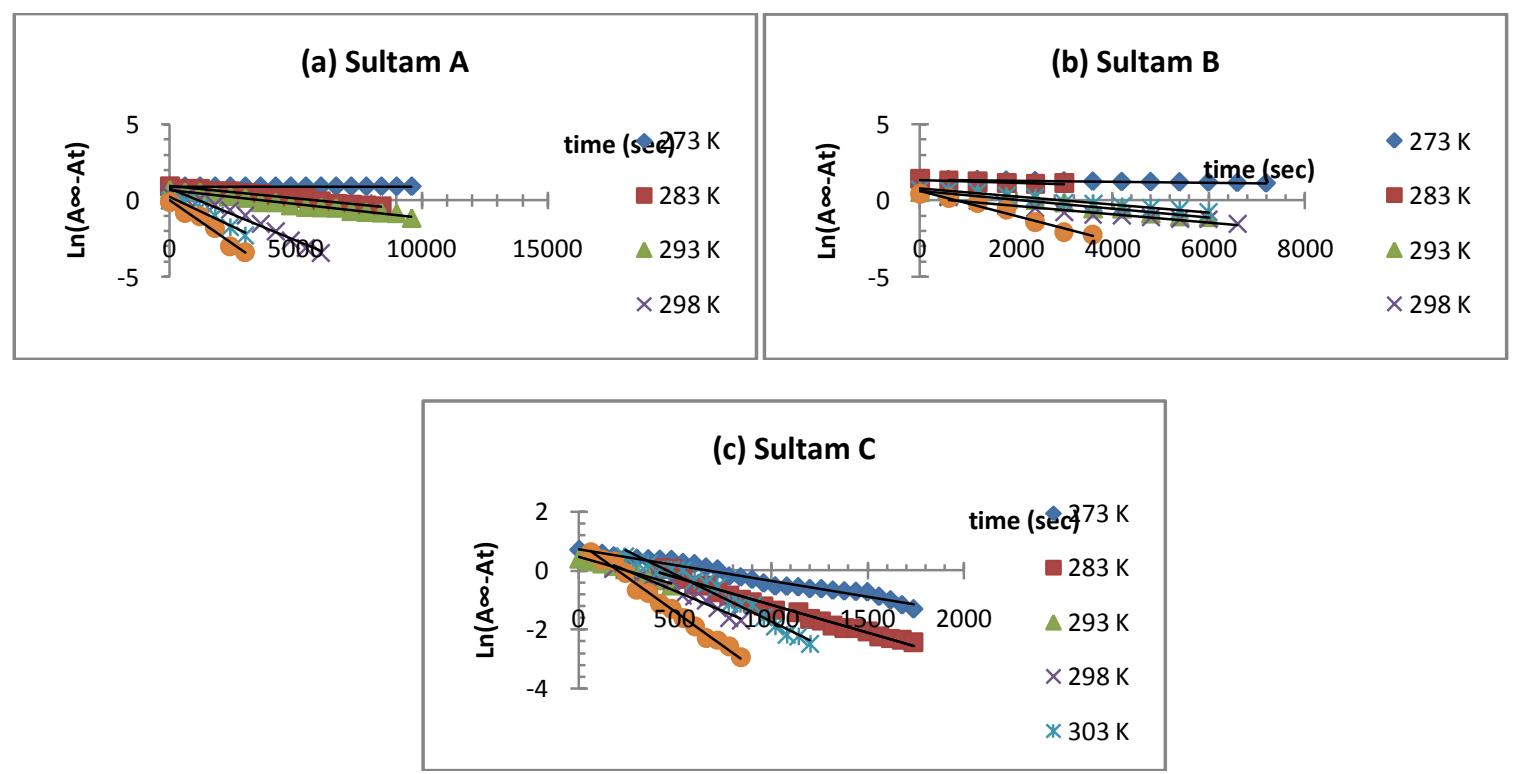

Figure (5): first order plot for the absorbance of the product of sultam (A, B, C) with bromine in chloroform using 1:15 molar ratio reactants. 
Table (2a): Observed rate constants, for the bromination of sultam $\mathrm{A}$ by $\mathrm{Br}_{2}$ with molar ratio (1:15).

\begin{tabular}{|l|l|l|l|}
\hline Temp. $(\mathbf{K})$ & $\mathbf{k}_{\text {obs }} \times \mathbf{1 0}^{-\mathbf{4}}\left(\mathbf{s e c}^{-\mathbf{1}}\right)$ & $\left.\mathbf{t}_{\mathbf{1} / \mathbf{2}} \mathbf{( s e c}\right)$ & $\mathbf{R}^{\mathbf{2}}$ \\
\hline $\mathbf{2 7 3}$ & 0.7 & 9900 & 0.966 \\
\hline $\mathbf{2 8 3}$ & 2 & 4620 & 0.981 \\
\hline $\mathbf{2 9 3}$ & 3 & 2165.6 & 0.980 \\
\hline $\mathbf{2 9 8}$ & 4.6 & 1506.5 & 0.949 \\
\hline $\mathbf{3 0 3}$ & 6 & 1155 & 0.987 \\
\hline $\mathbf{3 1 8}$ & 16 & 433.1 & 0.908 \\
\hline
\end{tabular}

Table (2b): Observed rate constants, for the bromination of sultam $\mathrm{B}$ by $\mathrm{Br}_{2}$ with molar ratio (1:15).

\begin{tabular}{|l|l|l|l|}
\hline Temp. $\mathbf{( K )}$ & $\mathbf{k}_{\text {obs }} \times \mathbf{1 0}^{-\mathbf{4}}\left(\mathbf{s e c}^{-\mathbf{1}}\right)$ & $\left.\mathbf{t}_{\mathbf{1} / \mathbf{2}} \mathbf{( s e c}\right)$ & $\mathbf{R}^{\mathbf{2}}$ \\
\hline $\mathbf{2 7 3}$ & 0.3 & 23100 & 0.973 \\
\hline $\mathbf{2 8 3}$ & 0.6 & 11550 & 0.982 \\
\hline $\mathbf{2 9 3}$ & 1 & 4950 & 0.976 \\
\hline $\mathbf{2 9 8}$ & 2 & 3465 & 0.976 \\
\hline $\mathbf{3 0 3}$ & 3 & 2310 & 0.968 \\
\hline $\mathbf{3 1 8}$ & 7 & 990 & 0.951 \\
\hline
\end{tabular}

Table (2c): Observed rate constants, for the bromination of sultam $\mathrm{C}$ by $\mathrm{Br}_{2}$ with molar ratio (1:15).

\begin{tabular}{|l|l|l|l|}
\hline Temp. $(\mathbf{K})$ & $\mathbf{k}_{\text {obs }} \times \mathbf{1 0}^{-4}\left(\mathbf{s e c}^{-1}\right)$ & $\mathbf{t}_{\mathbf{1} 2 \mathbf{2}}(\mathbf{s e c})$ & $\mathbf{R}^{2}$ \\
\hline $\mathbf{2 7 3}$ & 11 & 4614.675 & 0.976 \\
\hline $\mathbf{2 8 3}$ & 16 & 3172.589 & 0.940 \\
\hline $\mathbf{2 9 3}$ & 22 & 2307.337 & 0.983 \\
\hline $\mathbf{2 9 8}$ & 28 & 1812.908 & 0.963 \\
\hline $\mathbf{3 0 3}$ & 33 & 1538.225 & 0.960 \\
\hline $\mathbf{3 1 8}$ & 48 & 1057.53 & 0.978 \\
\hline
\end{tabular}

\subsubsection{Determination of thermodynamic activation parameters}

The rate constants for the reaction at the six different temperatures were plotted against $1 / \mathrm{T}$ and the activation energy $\left(E_{a}\right)$ was calculated from the slope of the Arrhenius plot (as shown in fig. (6)) which shows a good straight line with the slope of $\left(-E_{a} / R\right)$ as in the equation (2):

(2)

$$
\ln k=\ln A-E_{a} / R T
$$

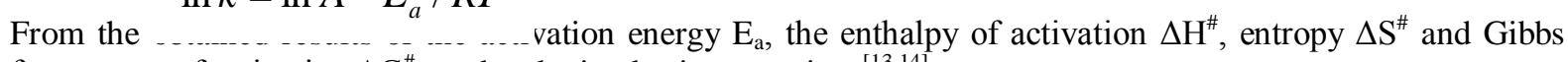
free energy of activation $\Delta \mathrm{G}^{\#}$ can be obtained using equations ${ }^{[13,14]}$ :

$$
\begin{array}{ll}
\Delta H^{\#}=E_{a}-R T & (3) \\
A=\frac{e K T}{h} e^{\frac{\Delta S^{\#}}{R}} & (5) \\
\Delta S^{\#}=R\left(\operatorname{Ln} A-\operatorname{Ln}\left(e k_{b} T / h\right)\right) & \\
\Delta G^{\#}=\Delta H^{\#}-T \Delta S^{\#} & \text { where } \mathrm{k}_{\mathrm{b}}=1.3806^{*} 10^{-23} \mathrm{~J} \mathrm{~K}^{-1}, \mathrm{~h}=6.626^{*} 10^{-34} \mathrm{~J} \text { sec. The Arrhenius }
\end{array}
$$

where $\mathrm{k}_{\mathrm{b}}=1.3806 * 10^{-23} \mathrm{~J} \mathrm{~K}^{-1}, \mathrm{~h}=6.626 * 10^{-34} \mathrm{~J}$ sec. The Arrhenius parameters, activated enthalpies and entropies obtained from the plotted graphs are tabulated in table (3) and (4).

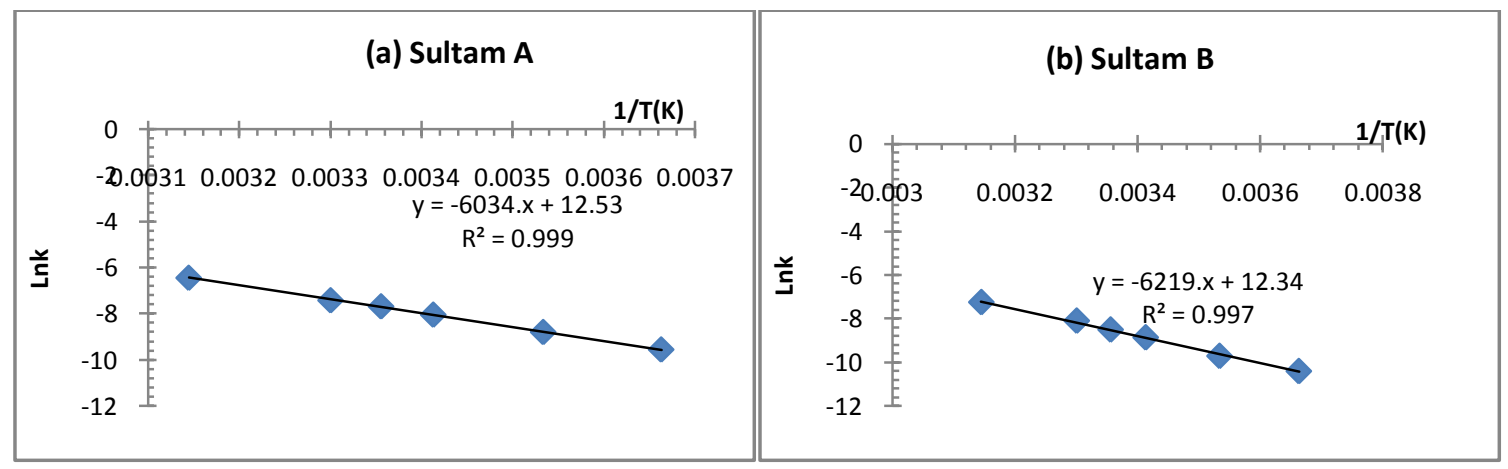




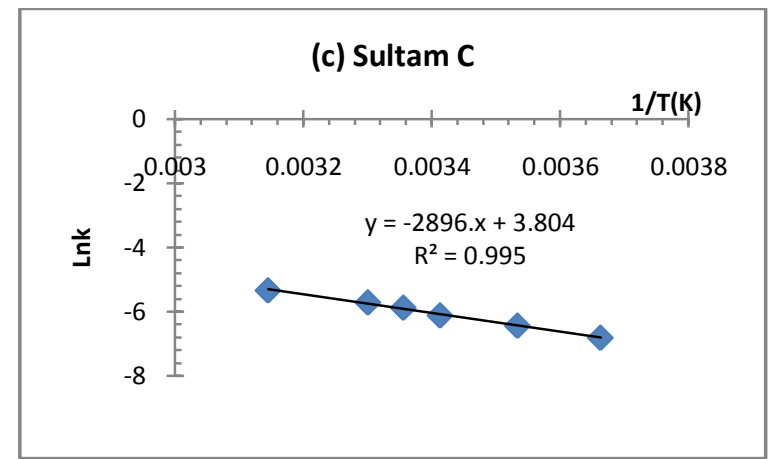

Figure (6): Arrhenius plots for bromination of sultams (A, B, C) at different temperatures using (1:15) molar ratio of sultam: $\mathrm{Br}_{2}$.

Table (3): Arrhenius parameters and entropies of activation for the Bromination of sultams (A, B, C) using $(1: 15)$ molar ratio of sultam: $\mathrm{Br}_{2}$.

\begin{tabular}{|l|l|l|l|l|}
\hline Sultam & $\begin{array}{l}\mathrm{E}_{\mathrm{a}} \\
\left(\mathrm{KJ}_{\mathrm{mol}} \mathrm{m}^{-1}\right)\end{array}$ & $\mathrm{R}^{2}$ & A-factor/ $\mathrm{s}^{-1}$ & $\begin{array}{l}\Delta \mathrm{S}^{\#} \\
\left(\mathrm{~J} \cdot \mathrm{mol}^{-1} \mathrm{~K}^{-1}\right) \text { at } 298 \mathrm{~K}\end{array}$ \\
\hline A & 50.167 & 0.999 & 277340.1472 & -149.020 \\
\hline B & 51.708 & 0.997 & 228661.952 & -150.625 \\
\hline C & 24084 & 0.995 & 44.898 & -221.590 \\
\hline
\end{tabular}

Table (4): Thermodynamic parameters for the bromination reaction of sultams (A, B,C) using (1:15) molar ratio of sultam: $\mathrm{Br}_{2}$.

\begin{tabular}{|c|c|c|c|}
\hline Sultam & Temp. (K) & $\begin{array}{l}\Delta \mathrm{H}^{\#} \\
\left(\mathrm{KJ}^{\prime} \cdot \mathrm{mol}^{-1}\right)\end{array}$ & $\begin{array}{l}\Delta \mathrm{S}^{\#} \\
\left(\mathrm{~J} \cdot \mathrm{mol}^{-1} \mathrm{~K}^{-1}\right)\end{array}$ \\
\hline \multirow{6}{*}{ A } & 273 & 47.897 & -148.292 \\
\hline & 283 & 47.814 & -148.591 \\
\hline & 293 & 47.731 & -148.879 \\
\hline & 298 & 47.689 & -149.020 \\
\hline & 303 & 47.648 & -149.158 \\
\hline & 318 & 47.523 & -149.560 \\
\hline \multirow{6}{*}{ B } & 273 & 49.439 & -149.896 \\
\hline & 283 & 49.356 & -150.195 \\
\hline & 293 & 49.272 & -150.484 \\
\hline & 298 & 49.231 & -150.625 \\
\hline & 303 & 49.189 & -150.763 \\
\hline & 318 & 49.065 & -151.165 \\
\hline \multirow{6}{*}{$\mathrm{C}$} & 273 & 21.815 & -220.861 \\
\hline & 283 & 21.731 & -221.160 \\
\hline & 293 & 21.648 & -221.449 \\
\hline & 298 & 21.607 & -221.590 \\
\hline & 303 & 21.565 & -221.728 \\
\hline & 318 & 21.440 & -222.130 \\
\hline
\end{tabular}

\subsubsection{Interpretation of the overall kinetic and thermodynamic results}

Typical plots between $\ln \left(\mathrm{A}_{\infty}-\mathrm{A}_{\mathrm{t}}\right)$ against (t) show excellent fit to equation(1) and were always linear, as shown in fig.(5) thus the assumption of pseudo-first order reaction is fully proved.

$\mathrm{k}$-values calculated in table (2) are very low which means the reactions are very slow and the rate of reaction of studied sultams follows the sequence:

$\mathrm{p}-\mathrm{OCH}_{3}>\mathrm{H}>\mathrm{p}-\mathrm{Cl}$

These are depending on the neucleophilicity of the amine $(\mathrm{N})$ group and the substituent on p-position. Table (2) shows the sequence $\mathrm{p}-\mathrm{OCH}_{3}>\mathrm{H}>\mathrm{p}-\mathrm{Cl}$ of the substituent groups, since these groups have different effect on the activating or deactivating of the rate of reactions. This is dependent on the strength of electronwithdrowing or electron-donating groups.

The comparison of the rate constant and the half time of the bromination reaction of unsubstitutedsultam(A) with other two different substituted sultams (B and C) at 298K is: 
1-The unsubstitutedsultam $(\mathrm{X}=\mathrm{H})$ was taken as a reference reaction rate for comparison $\left(\mathrm{k}=4.6 \times 10^{-4} \mathrm{sec}^{-1}\right)\left(\mathrm{t}_{1 / 2}=\right.$ $1506.5 \mathrm{sec}$.$) .$

2-When $(\mathrm{X}=\mathrm{p}-\mathrm{Cl})$ which is electron withdrawing group, it reduces electron density at the reaction center. As a result the rate of reaction decreased $\left(\mathrm{k}=2 \times 10^{-4} \mathrm{sec}^{-1}\right)$, i.e. $\mathrm{t}_{1 / 2}$ increased $\left(\mathrm{t}_{1 / 2}=3465 \mathrm{sec}\right.$. $)$.

3-When $\left(\mathrm{X}=\mathrm{p}-\mathrm{OCH}_{3}\right)$ which is electron donating group, thus enrich electron density at the reaction center of the formed activated complex. The rate of reaction increased $\left(\mathrm{k}=28 \times 10^{-4} \mathrm{sec}^{-1}\right)$, i.e. $\mathrm{t}_{1 / 2}$ decreased $\left(\mathrm{t}_{1 / 2}=1812.908\right.$ sec.).

We investigated the activation parameters for bromine attack to sultam in chloroform solution, and the results are visualized in fig.(6) and in tables(3) and (4). The highest activation energy $\left(\mathrm{E}_{\mathrm{a}}=51.708 \mathrm{KJmol}^{-1}\right)$ for the bromination of sultam B explains the slowness of the reaction, which means that the reactants need high energy for transition state, this is due to the electron withdrawing group $(\mathrm{p}-\mathrm{Cl})$ substituent, while $\mathrm{E}_{\mathrm{a}}$ value was smaller for sultam $\mathrm{C}\left(\mathrm{E}_{\mathrm{a}}=24.084 \mathrm{KJmol}^{-1}\right)$ that means easer reaction will occur.The values of $\Delta \mathrm{H}^{\#}$ are positive means consumes energy in its process. Relatively low values of (A) pre-exponential factor for sultam $\mathrm{C}$ were explained according to the transition state theory ${ }^{[15]}$, by the decrease in partition function of the transition state, $\mathrm{Q}^{*}{ }_{\mathrm{AB}}$, and the increase in the partition functions of the reactants, $\mathrm{Q}_{\mathrm{A}}$ and $\mathrm{Q}_{\mathrm{B}}$, according to the equation (7):

$$
A=\frac{K T}{h} * \frac{Q_{A B}^{*}}{Q_{A} Q_{B}}
$$

Which indicate the more rigid configuration with less degrees of freedom for the activated complex which has a simpler configuration than the reactant molecules. The study of the bromination of sultams are gave negative low values for $\Delta \mathrm{S}^{\#}$ as shown in table (4), which indicates the more rigid configuration with less degree of freedom for the activated complex than those of the reactant molecules.

$1-\Delta S^{\#}$ for the reaction between $\mathrm{Br}_{2}$ and unsubstitutedsultam $(\mathrm{X}=\mathrm{H})$ equal to $-149.020 \mathrm{JK}^{-1} \mathrm{~mol}^{-1}$ is considered as a reference for comparison with the substituted sultam.

$2-(\mathrm{X}=\mathrm{p}-\mathrm{Cl})$ the presence of electron withdrawing group lead to higher negative value of $\Delta \mathrm{S}^{\#}=-150.625 \mathrm{JK}^{-}$ ${ }^{1} \mathrm{~mol}^{-1}$, leads to a less aligned and unstable transition state.

3-Low negative value of $\Delta \mathrm{S}^{\#}=-221.590 \mathrm{~J} \mathrm{~K}^{-1} \mathrm{~mol}^{-1}$ for $\left(\mathrm{X}=\mathrm{p}-\mathrm{OCH}_{3}\right)$ for electron donating groups, which cause increasing electron density at the reaction center which allow for relatively better attack of the $\mathrm{Br}_{2}$ to obtained a more stable transition state.

\subsection{The bromination using sultam : $\mathrm{Br}_{2}(15: 1)$ molar ratio}

For Sultam:Br $\mathrm{Br}_{2}(15: 1)$ reaction, $\mathrm{H}^{1}-$ and $\mathrm{C}^{13}-\mathrm{nmr}$, IR and UV-data are very close to un substituted sultam. Of course a reaction has been achieved between $1 \mathrm{mmole}$ of bromine and $15 \mathrm{mmole}$ sultam but the product disappeared between the large quantities of sultam.

\subsection{The bromination using sultam : $\mathrm{Br}_{2}(1: 1)$ molar ratio}

The study of bromination of sultams also carried out using equi molar ratio of each reactants (sultam and $\mathrm{Br}_{2}$ ), the two and three dimensional absorption spectra, fig.(7)and(9), are represents the results of kinetic measurements for three sultams at six different temperatures (between 273-318K), and the variation of absorbance of the peaks with time are shown in fig.(10) as we see the absorbance of the product increase with time indicating that the reactions are clean forward processes, since no equilibrium was observed during kinetic runs.

The rate law can be expressed by the equation:

$\frac{d[\text { product }]}{d t}=k\left[\mathrm{Br}_{2}\right][$ Sultam $](8)$

These reactions were determined as second order equation; first-order with respect to each reactant and can be described by equation $(9)^{[16-19]}$ :

(9)

$$
\frac{A_{t}}{A_{\infty}\left(A_{\infty}-A_{t}\right)}=k t
$$

Which means that the straight line plot of $A_{t} /\left(A_{\infty}\left(A_{\infty}-A_{t}\right)\right)$ with the time $(t)$ has a slope $(k)$ which is the second order rate constant, the plots show excellent fit to the second order equation as shown in fig. (11) and the data are tabulated in the table $(5 \mathrm{a}, \mathrm{b}$ and $\mathrm{c})$. 


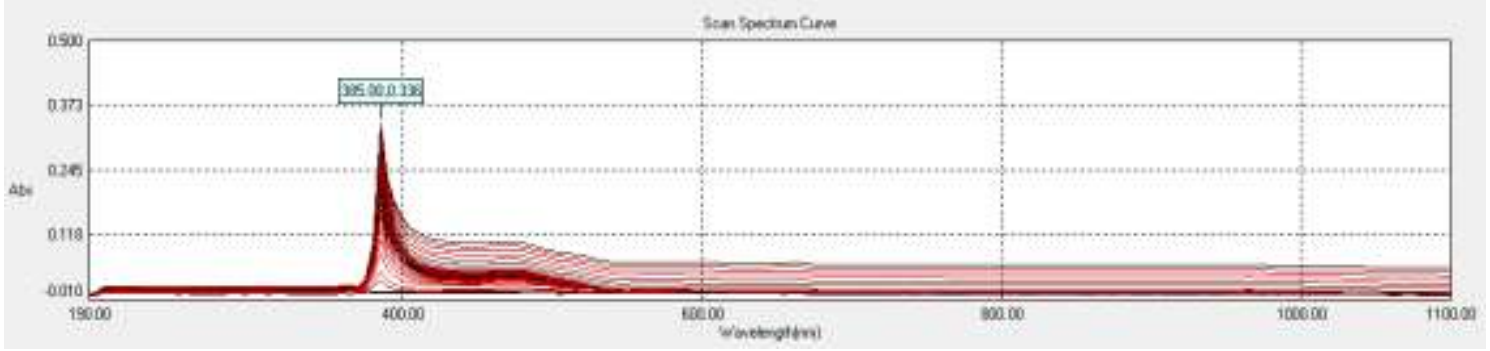

Figure (7)a: two dimensional spectrum for sultam A at 298K, (1:1) ratio.

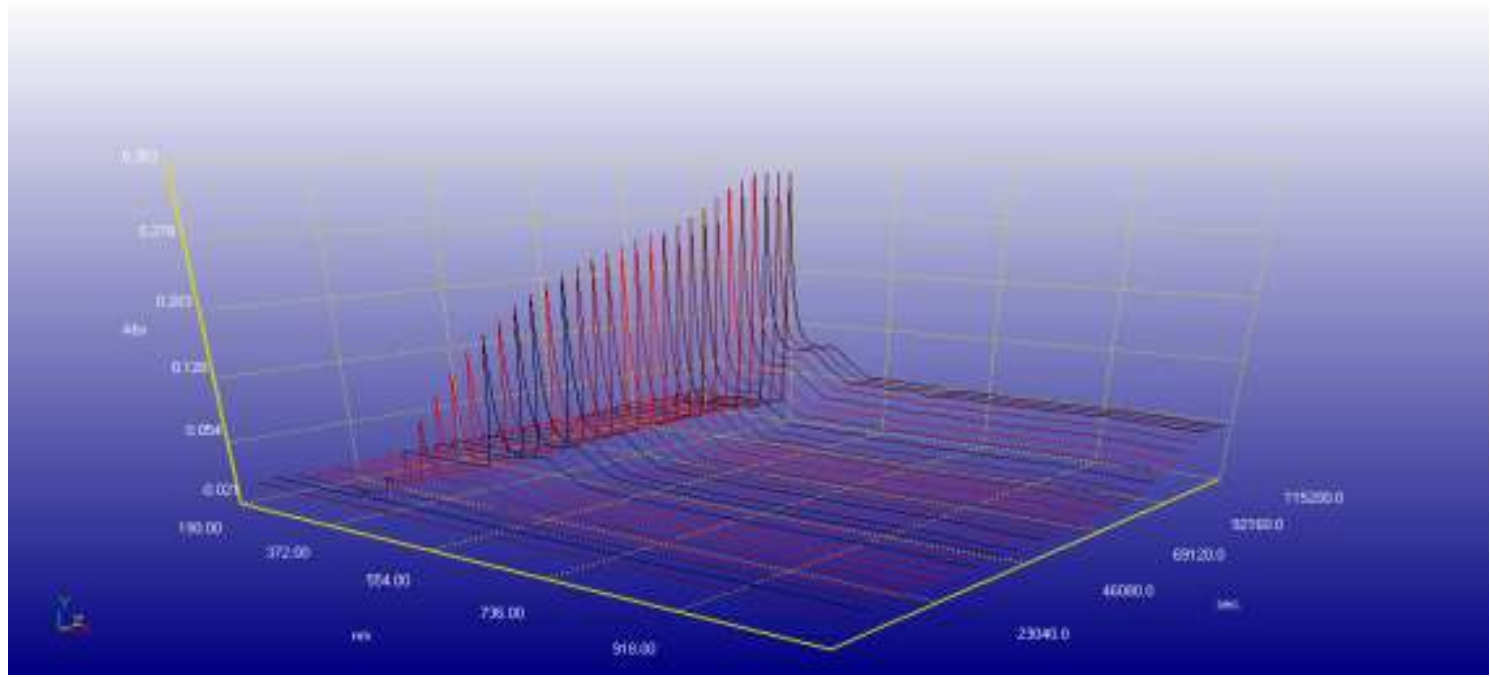

Figure (7)b: three dimensional spectrum for sultam A at 298K, (1:1) ratio.

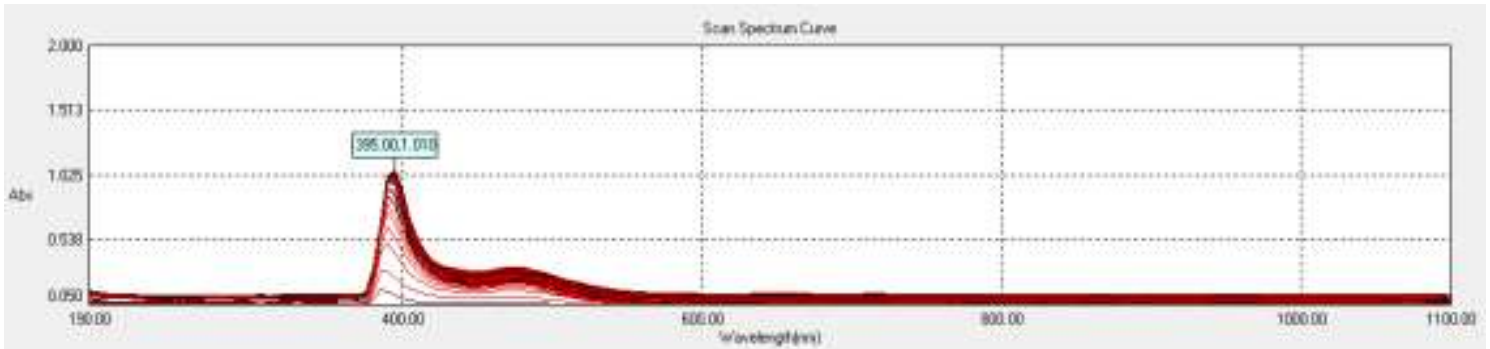

Figure (8)a: two dimensional spectrum for sultam B at 318K, (1:1) ratio.

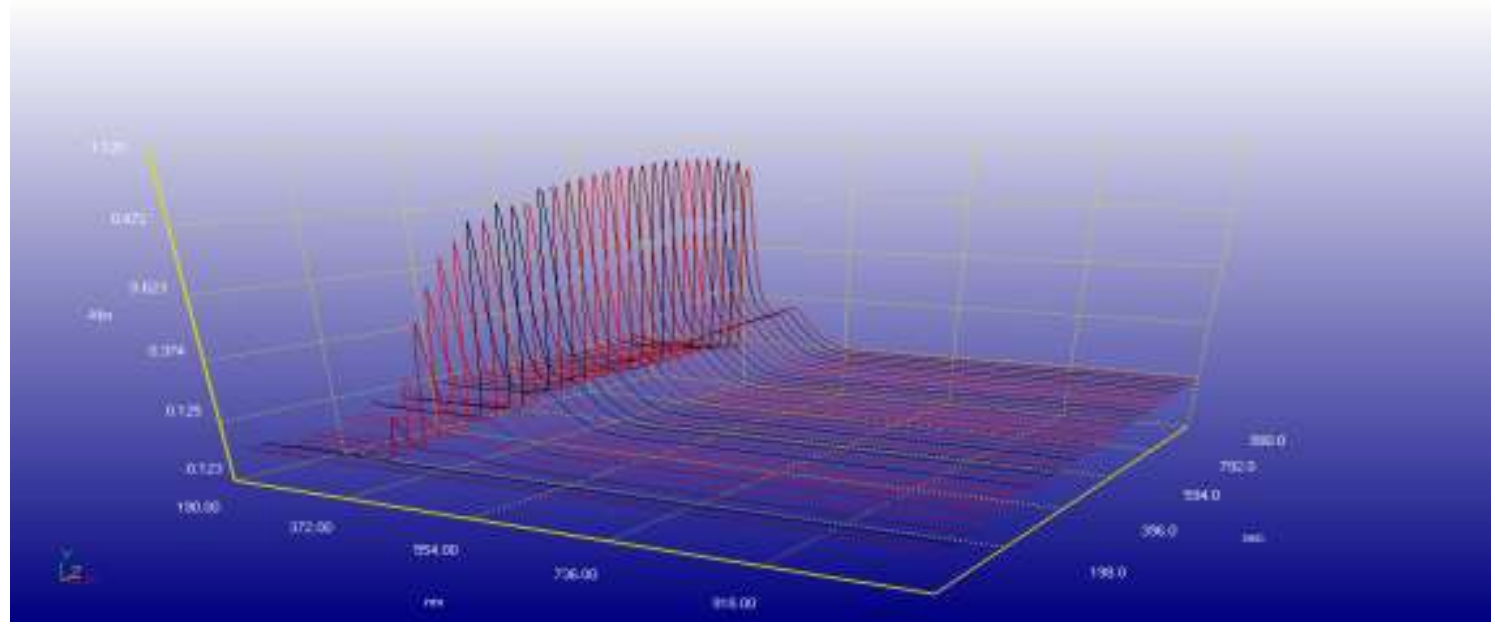

Figure (8)b: three dimensional spectrum for sultam B at 318K, (1:1) ratio. 


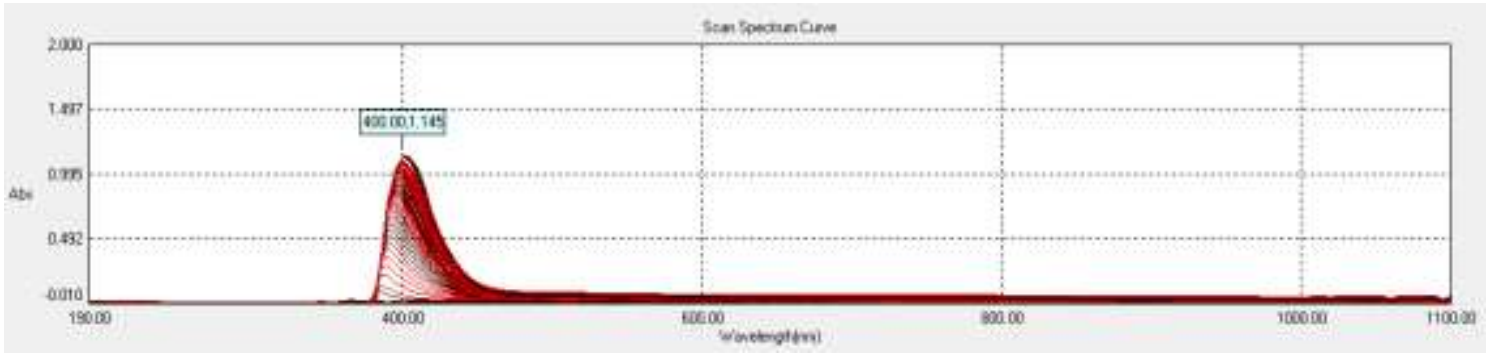

Figure (9)a: two dimensional spectrum for sultam C at 298K, (1:1) ratio.

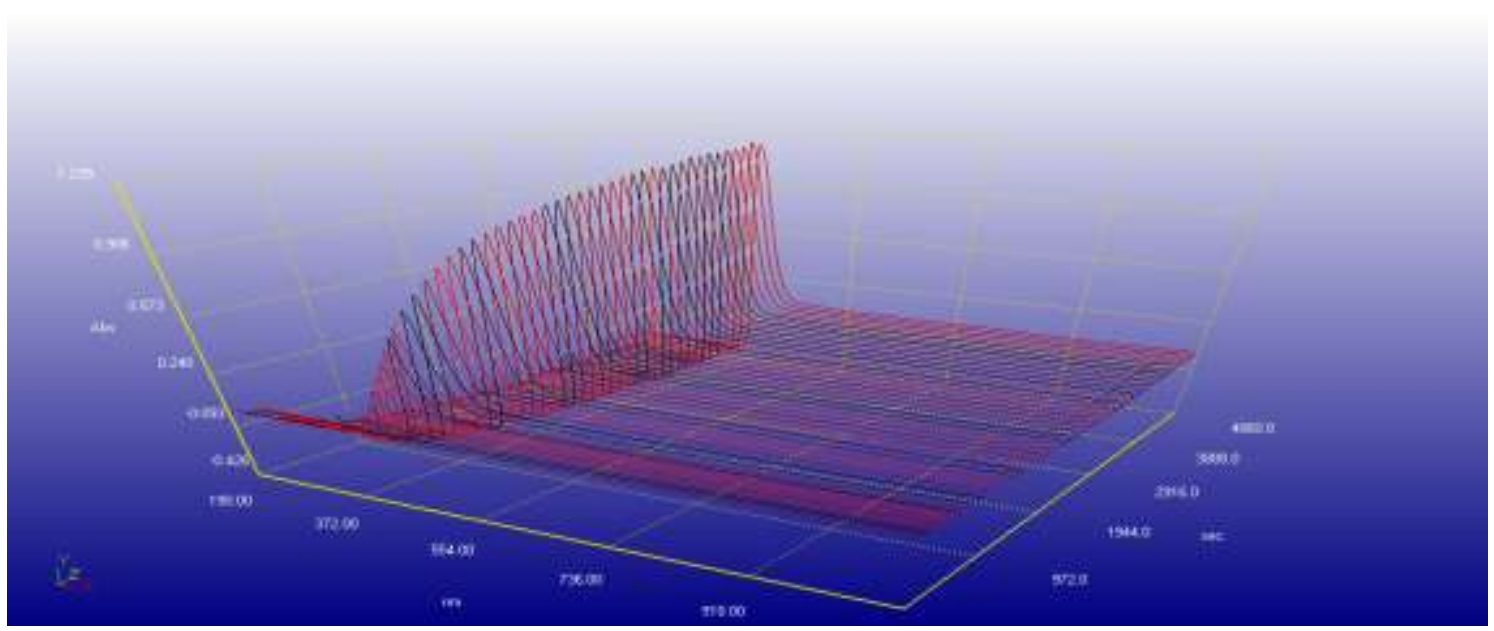

Figure (9)b: three dimensional spectrum for sultam C at 298K, (1:1) ratio.

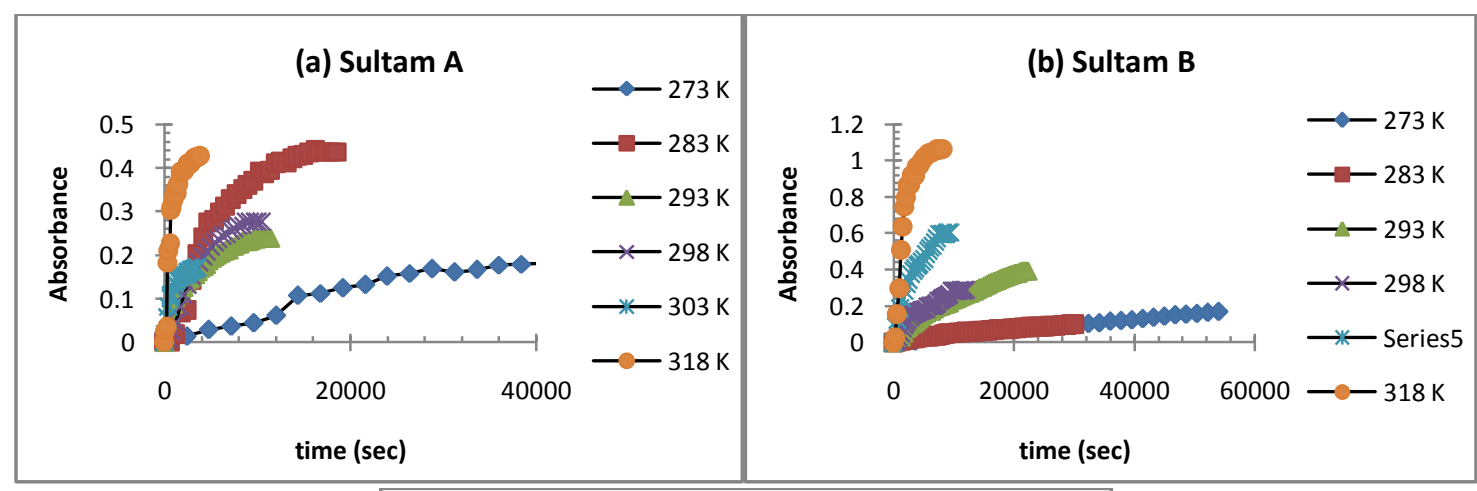

(c) Sultam C

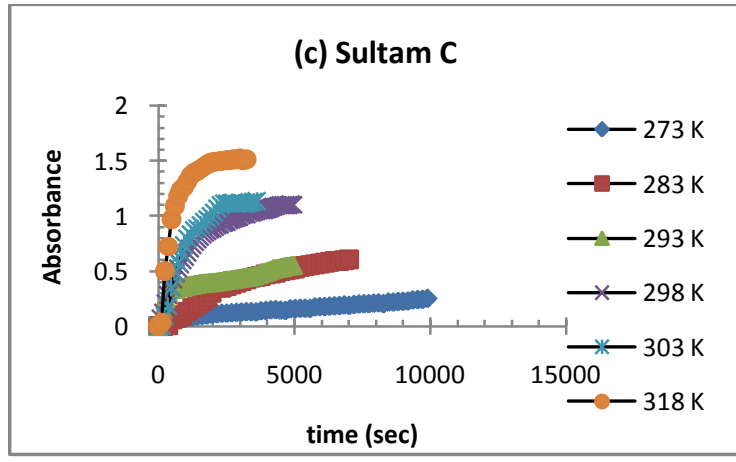

Figure (10): Variation of absorbance of the product with time for bromination of sultams (A, B, C) at different temperatures using (1:1) molar ratio of sultam: $\mathrm{Br}_{2}$. 


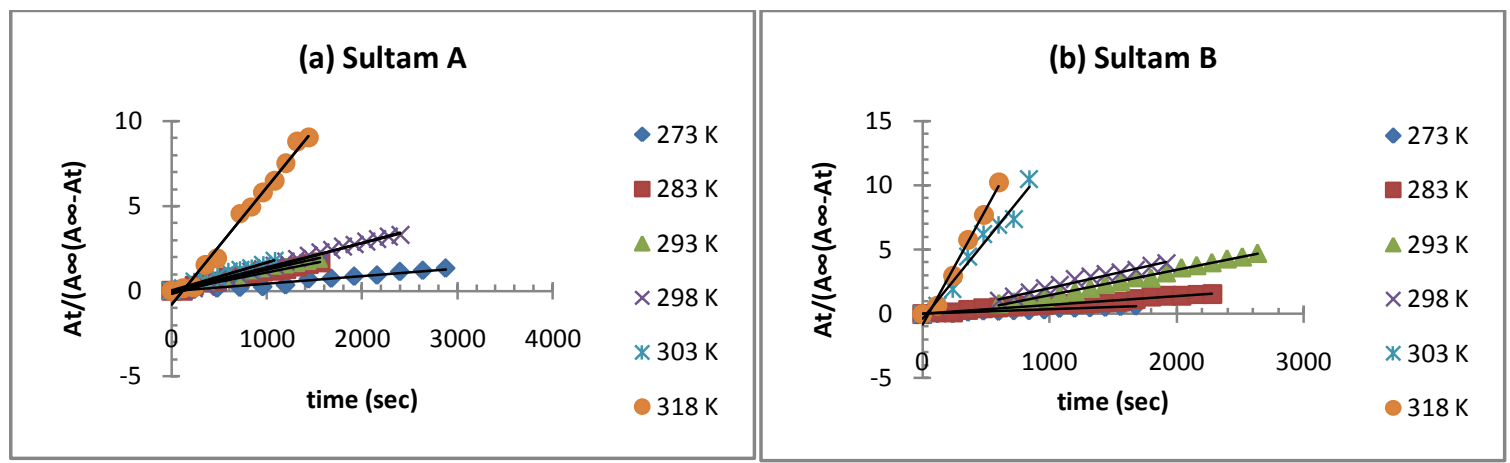

(c) Sultam C

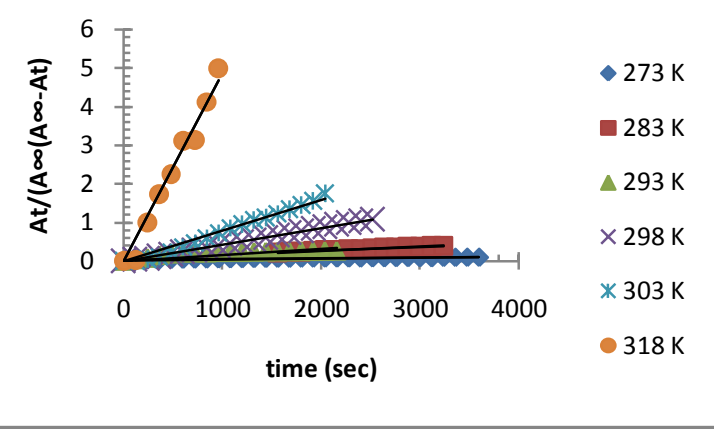

Figure (11): Second order plot for the absorbance of the product for bromination of sultams (A, B, C) at different temperatures using $(1: 1)$ molar ratio of sultam:

$\mathrm{Br}_{2}$.

Table (5)a: Observed rate constants, for the bromination of sultam A with $\mathrm{Br}_{2}$.

\begin{tabular}{|l|l|l|l|}
\hline Temp. $\mathbf{~ ( K ) ~}$ & $\mathbf{k}_{\text {obs }} \times \mathbf{1 0}^{-4}\left(\mathbf{s e c}^{-1} \cdot \mathbf{L} \cdot \mathbf{m o l} \mathbf{~}^{-1}\right)$ & $\mathbf{t}_{\mathbf{1} / \mathbf{2}}(\mathbf{s e c})$ & $\mathbf{R}^{\mathbf{2}}$ \\
\hline $\mathbf{2 7 3}$ & 2.3 & 22070.18 & 0.964 \\
\hline $\mathbf{2 8 3}$ & 6 & 8460.237 & 0.932 \\
\hline $\mathbf{2 9 3}$ & 14 & 3625.816 & 0.982 \\
\hline $\mathbf{2 9 8}$ & 21 & 2417.211 & 0.970 \\
\hline $\mathbf{3 0 3}$ & 31 & 1637.465 & 0.959 \\
\hline $\mathbf{3 1 8}$ & 93 & 545.8217 & 0.947 \\
\hline
\end{tabular}

Table (5)b: Observed rate constants, for the bromination of sultam $\mathrm{B}$ with $\mathrm{Br}_{2}$.

\begin{tabular}{|l|l|l|l|}
\hline Temp. (K) & $\mathbf{k}_{\text {obs }} \times \mathbf{1 0} \mathbf{0}^{-4}\left(\mathbf{s e c}^{-\mathbf{1}} \mathbf{.} \mathbf{L} \cdot \mathbf{m o l} \mathbf{H}^{-\mathbf{1}}\right)$ & $\mathbf{t}_{\mathbf{1} / 2}(\mathbf{s e c})$ & $\mathbf{R}^{\mathbf{2}}$ \\
\hline $\mathbf{2 7 3}$ & 0.00012 & 42301.18 & 0.984 \\
\hline $\mathbf{2 8 3}$ & 0.00036 & 14100.39 & 0.976 \\
\hline $\mathbf{2 9 3}$ & 0.001 & 5076.142 & 0.994 \\
\hline $\mathbf{2 9 8}$ & 0.0016 & 3172.589 & 0.972 \\
\hline $\mathbf{3 0 3}$ & 0.0025 & 2030.457 & 0.982 \\
\hline $\mathbf{3 1 8}$ & 0.01 & 507.6142 & 0.910 \\
\hline
\end{tabular}

Table (5)c: Observed rate constants, for the bromination of sultam $\mathrm{C}$ with $\mathrm{Br}_{2}$.

\begin{tabular}{|c|c|c|c|}
\hline Temp. (K) & $\mathbf{k}_{\mathrm{obs}} \times 10^{-4}\left(\sec ^{-1} \cdot \mathbf{L} \cdot \mathrm{mol}^{-1}\right)$ & $\mathbf{t}_{1 / 2}(\mathrm{sec})$ & $\mathbf{R}^{2}$ \\
\hline 273 & 11 & 4614.675 & 0.939 \\
\hline 283 & 15 & 3384.095 & 0.964 \\
\hline 293 & 21 & 2417.211 & 0.974 \\
\hline 298 & 25 & 2030.457 & 0.944 \\
\hline 303 & 30 & 1692.047 & 0.946 \\
\hline 318 & 44 & 1153.669 & 0.962 \\
\hline
\end{tabular}



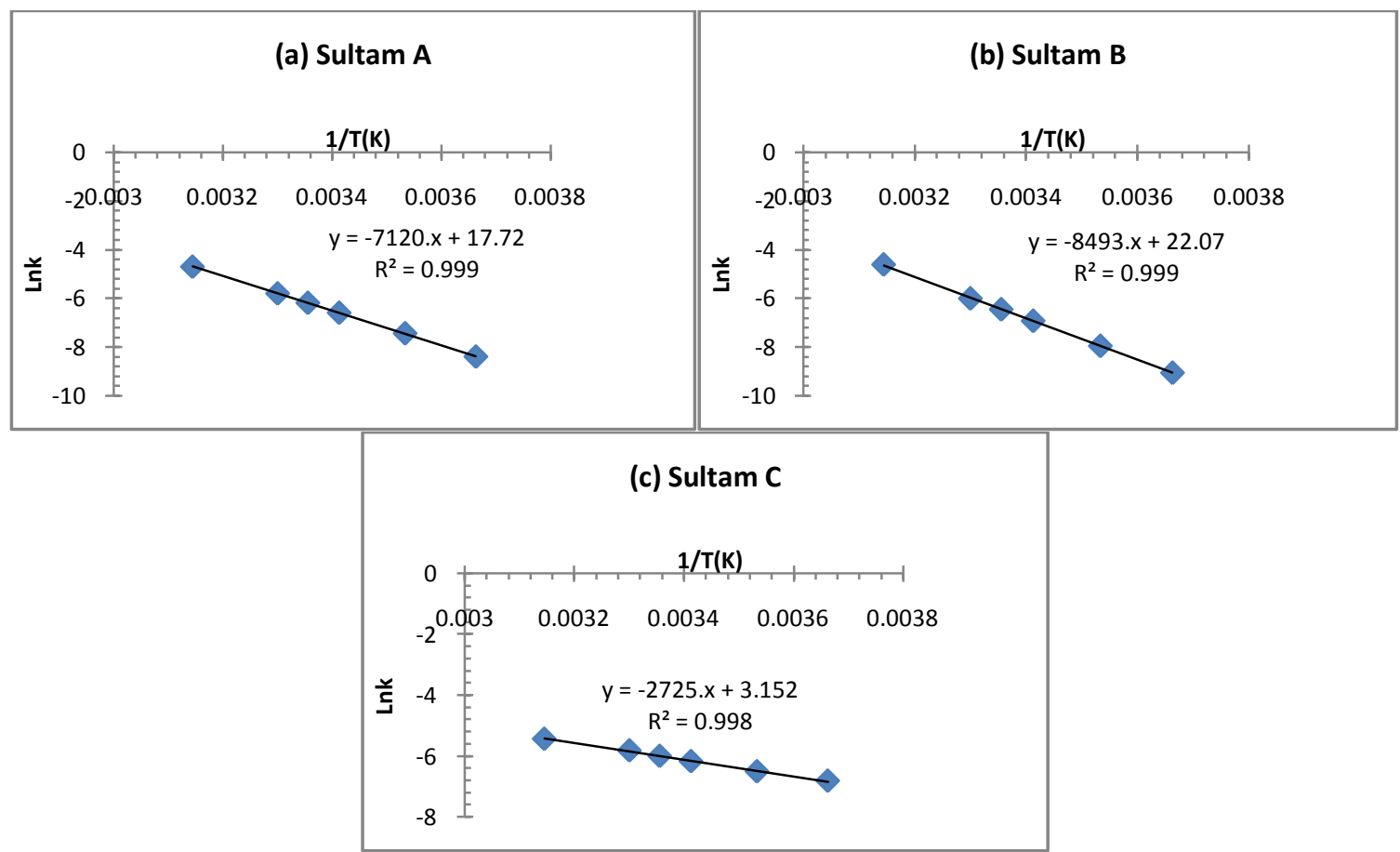

Figure (12): Arrhenius plots for bromination of sultams (A, B, C) at different temperatures using (1:1) molar ratio of sultam: $\mathrm{Br}_{2}$.

Table (6): Arrhenius parameters and entropies of activation for the bromination of sultams (A, B, C) using (1:1) molar ratio of sultam: $\mathrm{Br}_{2}$.

\begin{tabular}{|l|l|l|l|l|}
\hline Sultam & $\begin{array}{l}\mathrm{E}_{\mathrm{a}} \\
\left(\mathrm{KJ}_{\mathrm{mol}}{ }^{-1}\right)\end{array}$ & $\mathrm{R}^{2}$ & $\begin{array}{l}\text { A-factor } \\
\left(\mathrm{s}^{-1} \cdot \mathrm{L} \cdot \mathrm{mol}^{-1}\right)\end{array}$ & $\begin{array}{l}\Delta \mathrm{S}^{\#} \\
\left(\mathrm{~J} \cdot \mathrm{mol}^{-1} \mathrm{~K}^{-1}\right)\end{array}$ \\
& 59.201 & 0.999 & 49873482.17 & -105.854 \\
\hline A & 70.614 & 0.999 & 3867986793 & -69.680 \\
\hline B & 22.657 & 0.998 & 23.392 & -227.010 \\
\hline C & &
\end{tabular}

Table (7): Thermodynamic parameters for the bromination reaction of sultams (A, B, C) using (1:1) molar ratio of sultam: $\mathrm{Br}_{2}$.

\begin{tabular}{|c|c|c|c|}
\hline Sultam & Temp. (K) & $\begin{array}{l}\Delta \mathrm{H}^{\#} \\
\left(\mathrm{KJ}^{\prime} \cdot \mathrm{mol}^{-1}\right)\end{array}$ & $\begin{array}{l}\Delta \mathrm{S}^{\#} \\
\left(\mathrm{~J} \cdot \mathrm{mol}^{-1} \mathrm{~K}^{-1}\right)\end{array}$ \\
\hline \multirow{6}{*}{ A } & 273 & 56.931 & -105.125 \\
\hline & 283 & 56.848 & -105.424 \\
\hline & 293 & 56.765 & -105.713 \\
\hline & 298 & 56.723 & -105.854 \\
\hline & 303 & 56.682 & -105.992 \\
\hline & 318 & 56.557 & -106.394 \\
\hline \multirow{6}{*}{ B } & 273 & 68.344 & $\begin{array}{l}-68.951 \\
\end{array}$ \\
\hline & 283 & 68.261 & $\begin{array}{l}-69.250 \\
\end{array}$ \\
\hline & 293 & 68.178 & $\begin{array}{l}-69.539 \\
\end{array}$ \\
\hline & 298 & 68.136 & -69.680 \\
\hline & 303 & 68.094 & -69.818 \\
\hline & 318 & 67.970 & -70.220 \\
\hline \multirow{6}{*}{ C } & 273 & 20.387 & -226.282 \\
\hline & 283 & 20.304 & -226.581 \\
\hline & 293 & 20.221 & -226.870 \\
\hline & 298 & 20.179 & -227.010 \\
\hline & 303 & 20.138 & -227.149 \\
\hline & 318 & 20.013 & -227.550 \\
\hline
\end{tabular}




\subsubsection{Interpretation of the overall kinetic and thermodynamic results}

The kinetic results for the bromination of sultams with different substituents are summarized previously in table ((5)a,b and c)).

These reactions were found to obey the second order equation leading to linear plots toward completion of the reaction. Furthermore, plots demonstrate very good agreement between represented runs. These observations indicated that the reactions were second order equation; first-order with respect to each reactant.

The $\mathrm{k}$-values and $\mathrm{t}_{1 / 2}$ are very low, comparing $\mathrm{k}$-values of unsubstitutedsultam with other two different substituted sultam at $298 \mathrm{~K}$ :

1. Bromination of sultame $A(X=H)$ proceed slowly $\left(k=21 \times 10^{-4} \mathrm{sec}^{-1} \mathrm{Lmol}^{-1}\right)\left(\mathrm{t}_{1 / 2}=2417.211 \mathrm{sec}\right)$.

2. Reaction of $\mathrm{Br}_{2}$ with sultam $\mathrm{B}(\mathrm{X}=\mathrm{p}-\mathrm{Cl})$ is very slow comparing with sultam $\mathrm{A}$ this is due to the electron withdrawing effect of the chlorine which deactivate the reaction center, which leads to the decrease in $\mathrm{k}$ value $\left(\mathrm{k}=16 \times 10^{-4} \mathrm{sec}^{-1} \mathrm{Lmol}^{-1}\right)$ and $\mathrm{t}_{1 / 2}$ increased $\left(\mathrm{t}_{1 / 2}=3172.589 \mathrm{sec}\right)$.

3. When $\left(\mathrm{X}=\mathrm{p}-\mathrm{OCH}_{3}\right)$ which is electron donating group, which activate the reaction center and the rate of reaction increased $\left(\mathrm{k}=25 \times 10^{-4} \mathrm{sec}^{-1} \mathrm{Lmol}^{-1}\right)\left(\mathrm{t}_{1 / 2}=2030.457 \mathrm{sec}\right)$. $(\mathrm{H})>\mathrm{k}(\mathrm{p}-\mathrm{Cl})$.

General effect of substituents on the sultam makes the rate constant in proportion as: $\mathrm{k}\left(\mathrm{OCH}_{3}\right)>\mathrm{k}$

Inspection of table (6) discloses the apparent changes in the activation energies of bromination processes. These changes afford further evidence about the relative reactivates of the substituted compounds towards bromination. In our present work, the bromination processes of all reactants were of small activation energies which vary within $22-71 \mathrm{KJmol}^{-1}$. The variation of their values may be attributed to electron donating or withdrawing capabilities of the attached substituent that can affect on the formation of intermediate and its decay to the product.

In the bromination of sultams $\left(\mathrm{X}=\mathrm{H}, \mathrm{p}-\mathrm{Cl}, \mathrm{p}-\mathrm{OCH}_{3}\right)$, it can be noticed that all of their $\mathrm{E}_{\mathrm{a}}$ value vary in line with rate of reaction i.e. a fast reaction requires low $\mathrm{E}_{\mathrm{a}}$ and vice versa. This observation can be explained by the nucliophilic substitution properties in the presence of electron donating group at the ring of sultam which lead to decreasing the repulsive forces during nucliophilic substitution giving rise to a higher chance of $\mathrm{Br}^{+}$to attack the reaction center compared with unsubstitutedsultam and vice versa for electron withdrawing group like $\mathrm{p}-\mathrm{Cl}$. The differences in activation energies were found to vary in the following order of: $\mathrm{p}-\mathrm{Cl}>\mathrm{H}>\mathrm{p}-\mathrm{OC} \mathrm{H}_{3}$ The (A) pre-exponential factor and its corresponding entropy of activation $\Delta \mathrm{S}^{\#}$ are other two important factors that give evidences on the reaction mechanism. Table (7) shows the negative values of the $\Delta S^{\#}$ of the bromination process under study, indicating the formation of a restricted high polar transition state or intermediate which suffers from lack of certain degrees of freedom as compared to the mother reactants. The decrease in the values of A-factor provides an important indication about the stability of the high polar transition state and hence gives good support for explaining the reasons of the differences in the values of rate constants. The lower value of $\mathrm{A}$-factor or $\Delta \mathrm{S}^{\#}$ means the more rigid the formed dipolar transition state, which leads to a faster process, as it was mentioned before.

It is noteworthy that $\Delta \mathrm{S}^{\#}$ value for the chloro-substituted sultam; quite higher value $\left(-69.68 \mathrm{JK}^{-1} \mathrm{~mol}^{-1}\right)$ than others. This is quite consistent with the rate constant results. It is possible for sultamto form a dipolar activated complex, due to electron withdrawing ability of the $\mathrm{p}-\mathrm{Cl}$ group, results in increase the entropy of activation. The presence of the $\mathrm{p}-\mathrm{CH}_{3}$ group (electron donating group) leads to a lower value of $\Delta \mathrm{S}^{\#}(\approx-$ $227.01 \mathrm{JK}^{-1} \mathrm{~mol}^{-1}$ ) this highly electron donating group causes to a high aligned and highly stable transition state, since it affords a low density of electrons to the reaction center and decreases the repulsive force. It is obvious from the above discussion, that electronic (withdrawing and releasing) effects have produced such major variations in $\Delta \mathrm{S}^{\#}$ values which become to vary in the following order: $\quad \mathrm{p}-\mathrm{Cl}>\mathrm{H}>\mathrm{p}-\mathrm{OCH} \mathrm{H}_{3}$

\subsection{Reaction mechanism}

With the assumption that 1,2-thazine nuclei are nucleophilic, and with the sure knowledge that alkene linkages are present in such nuclei, it is reasonable to picture at least the initial stages of aromatic substitution as being exactly analogous to the typical nucleophilic additive reactions. Hence the accepted mechanism for the reaction was (scheme 2$)^{[20]}$ : 


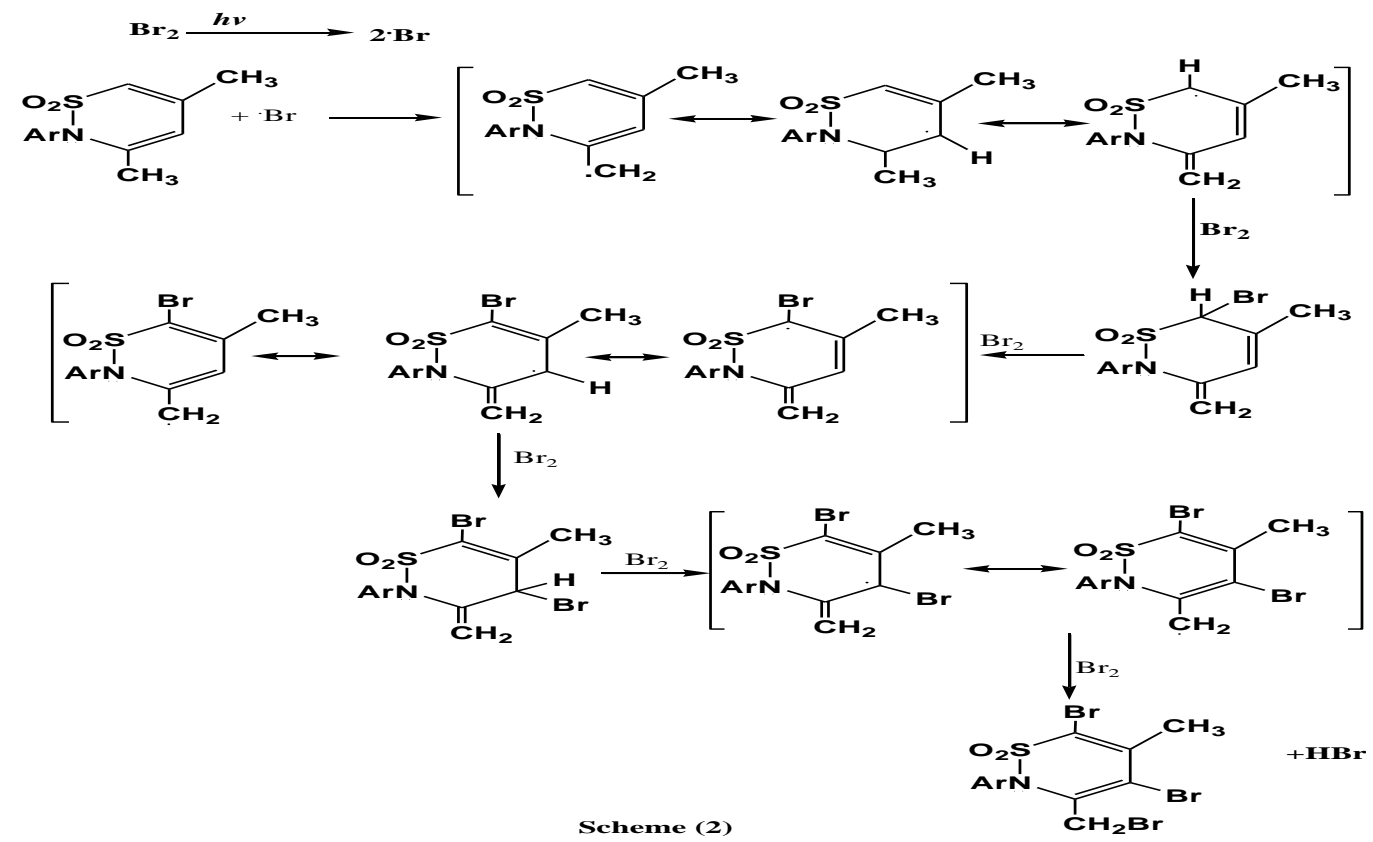

\section{Conclusion}

The proposed experimental techniques that have been used in kinetics and thermodynamic studies are quite simple and free from rigid experimental conditions and are characterized by wide linear dynamic ranges and high sensitivity. The importance of the present investigation is to demonstrate the possibility of using a modern in situ spectroscopic method (UV-Vis spectroscopy) to investigate these reaction kinetics.

\section{Acknowledgements}

My deepest appreciation and gratitude to the higher education council, Salahaddin university-Erbil.

\section{References}

[1] C. Hansch, and P.G. Sammes, Comprehensive Medicinal Chemistry (Pergamon press, Oxford, 1990).

[2] P. R. Hanson, D. A. Probst, R. E. Robinson, and M. Yau, Tetrahedron let. 40, 4761, 1999.

[3] P.J. Seyden, Chiral Auxiliaries and Ligands in Asymmetric synthesis, (Wiley, New York, 1995).

[4] R.C. Brown, J.L. Castro, and J-D Moriggi, Tetrahedron Let. 41, 3681, 2000.

[5] A. Jenkins, IUPAC compendium of chemical Terminology, $2^{\text {nd }}$ Ed. 67, 1370, 1995.

[6] H. Burckhardt, T. Bonner, Bonu, Germany, U.S. Pattent. No. 2,917,512, Dec.15, 1959

[7] F. Hans, D. Beeck, and H. Tummes, Duisburg-Meiderich, Germany, U.S. pattent. No. 2,866,786, Dec. 30 (1958)

[8] R.R. Braim, K.A. Ketuly, A.H. Hadi and H. KhalediActaCrystaaographic o2775, E67, (2011).

[9] E. Fanghenel, H. Mohammed, A.M. Richter and R. Radeglia, Journal of Practical Chemistry, 326, 545, (1984).

[10] E. Fanghanel, H.A. Muhammed and Y. Keta, Journal Practical Chemistry, 324,(1982).

[11] A.P. Uthman, P.J. Demlein, T.D. Allston, M.C. Withiam, M.J. McClements, and G.A. Takacs, J. Phys. Chem., 82, $2252,1978$.

[12] A. Semnani, H. R. Pouretedal, and M. H. Keshavarz Bull. Korean Chemical Society, 27, 6, 2006.

[13] G.M. Barrow. physical chemistry (McGrow Hill Inc), 4th Ed., 1979.

[14] B.G. Gowenlock, Quart. Rev., 140, 1331960.

[15] R.W. Missen, Ch. A. Mims, and B. A. Saville; Introduction to chemical reaction engineering and kinetics, 1998.

[16] Ch. G. Hill, An introduction to chemical engineering kinetics and reactor design John Wiley and Sons New York, 1977.

[17] P.W. Atkins Physical chemistry, (Oxford University Press, USA 5th Ed., 1995).

[18] K.J. Laidler A glossary of terms used in chemical kinetics, including reaction dynamics Pure \& Applied Chemistry, 68, (1), 1996, $149-192$.

[19] S. Alberty, J. Robert and A. Robert Physical chemistry (John Wiley and sons, Inc. New York, 3rd edition, 2001).

[20] E. Earl Royals Advanced organic chemistry (prentice Hall United States America, 1961). 